\title{
Adaptive gradients and isolation-by-distance with postglacial migration in Picea sitchensis
}

\author{
M Mimura and SN Aitken \\ Forest Sciences and Centre for Forest Gene Conservation, University of British Columbia, Vancouver, Canada
}

Fossil pollen records suggest rapid migration of tree species in response to Quaternary climate warming. Long-distance dispersal and high gene flow would facilitate rapid migration, but would initially homogenize variation among populations. However, contemporary clinal variation in adaptive traits along environmental gradients shown in many tree species suggests that local adaptation can occur during rapid migration over just a few generations in interglacial periods. In this study, we compared growth performance and pollen genetic structure among populations to investigate how populations of Sitka spruce (Picea sitchensis) have responded to local selection along the historical migration route. The results suggest strong adaptive divergence among populations (average $Q_{\mathrm{ST}}=0.61$ ), corresponding to climatic gradients. The population genetic structure, determined by microsatellite markers $\left(R_{\mathrm{ST}}=0.09 ; \quad F_{\mathrm{ST}}=0.11\right)$, was higher than previous estimates from less polymorphic genetic markers. The significant correlation between geographic and pollen haplotype genetic $\left(R_{\mathrm{ST}}\right)$ distances $(r=0.73, P<0.01)$ indicates that the current genetic structure has been shaped by isolation-by-distance, and has developed in relatively few generations. This suggests relatively limited gene flow among populations on a recent timescale. Gene flow from neighboring populations may have provided genetic diversity to founder populations during rapid migration in the early stages of range expansion. Increased genetic diversity subsequently enhanced the efficiency of local selection, limiting gene flow primarily to among similar environments and facilitating the evolution of adaptive clinal variation along environmental gradients.

Heredity (2007) 99, 224-232; doi:10.1038/sj.hdy.6800987; published online 9 May 2007

Keywords: range shift; adaptation; gene flow; population size; adaptive cline; conifers

\section{Introduction}

In response to climate change during the Quaternary Period, species' ranges repeatedly shifted northward and southward (Hewitt, 1996). Climate change over time and space shifted the intensity and direction of natural selection toward new local optima. Although a whole species range could shift to spatially track the same climate envelope as defined by the same range of temperature and moisture, the species would still have to adapt to some new environmental conditions including biotic agents, species interactions or new photoperiods. Species' range shift driven by climate change is not just the movement of an entire range, but involves migration and adaptation to new environments at a large scale (Davis and Shaw, 2001) or across topographic and environmental variation at a local scale (Campbell, 1979).

Fossil pollen records suggest rapid migration of tree species in response to postglacial warming (Davis, 1981; Davis and Shaw, 2001). Migration rates estimated for several tree species exceed $100 \mathrm{~m}$ /year (Clark, 1998). Long-distance dispersal may be a key feature of the rapid migration of tree species (Clark, 1998; Clark et al., 2003).

Correspondence: Professor SN Aitken, Forest Sciences and Centre for Forest Gene Conservation, University of British Columbia, 3041-2424 Main Mall, Vancouver, BC, Canada V6T 1Z4.

E-mail: sally.aitken@ubc.ca

Received 15 May 2006; revised 27 October 2006; accepted 16 February 2007; published online 9 May 2007
High gene flow and high genetic variation within populations, typical in tree species (Hamrick et al., 1992), may have been enhanced by long-distance dispersal.

Despite past rapid migration during the Quaternary, tree species exhibit clinal phenotypic values along environmental gradients (Morgenstern, 1996). Tree species migrate quickly, and despite the homogenizing effects of high subsequent gene flow, populations still adapt in relatively few generations to new environments. Davis and Shaw (2001) proposed that gene flow from neighboring populations plays a crucial role in species' range shift in response to linear environmental shifts. During such environmental changes, gene flow from neighboring populations can provide somewhat preadapted alleles to founder populations, and with genetic recombination and selection, may enhance local adaptation. Thus, a migrating population may adapt to a new environment through a combination of gene flow and selection. Such species should show isolation-by-distance (IBD) genetic structure following the stepping stone migration model in relatively few generations, while exhibiting adaptive population divergence across the range.

The concept of IBD was originally addressed by Wright (1943). In this model, the level of gene flow (or number of migrants) is expected to decrease with increasing distance between populations under equilibrium conditions. In theory, IBD should be more pronounced at equilibrium between genetic drift and 
gene flow (Slatkin, 1993), thus it is expected that IBD will be seen in long-established populations but may not be detectable in recently established populations (for example Sharbel et al., 2000; Genton et al., 2005). Peterson and Denno (1998) conducted meta-analyses in host insect species and found that high- and low-dispersal species showed less IBD compared to species with moderate dispersal capability. This occurs because high gene flow homogenizes variation among populations and low gene flow results in effective isolation and genetic drift. We expect to see IBD when gene flow from neighboring populations is stronger than the long-term effects of long-distance gene flow on population genetic structure.

Migration in response to postglacial warming has left signatures on population structure in many species. A study of chloroplast DNA (cpDNA) of herbaceous and woody plants distinguished northern and southern genotypes for six of the seven species analyzed along the Pacific coast of North America (Soltis et al., 1997). This north-south population structure suggests either a pattern of leading edge migration or the presence of glacial refugia in both northern and southern areas. Sitka spruce (Picea sitchensis (Bong.) Carr.) did not, however, show the same phylogeographic pattern and had little geographic structure in cpDNA (Soltis et al., 1997).

Sitka spruce is a wind-pollinated, predominantly outcrossing conifer species, endemic to North America. The current range of this species spans more than $22^{\circ}$ latitude from northern California to Kodiak Island in southwest Alaska. At the last glacial maximum, the southern range limit of Sitka spruce reached at least $22 \mathrm{~km}$ south of San Francisco Bay, CA (Daubenmire, 1967). Sitka spruce extended its northern range limit from south of Puget Sound, Washington, in the early Pleistocene, reaching the current northern limit on Kodiak Island in Alaska approximately 400 years ago. Growth performance of populations exhibits a strong correlation with environmental gradients such as latitude (Harris, 1978; Xu et al., 2000). The absence of genetic differences among populations in cpDNA in Sitka spruce, which is paternally inherited in the Pinaceae and maternally inherited in the angiosperm species studied by Soltis et al. (1997), suggests that high pollen flow across the wide range has homogenized population genetic structure. Similar results were found using eight sequence-tagged-site (STS) markers in nuclear DNA $\left(F_{\mathrm{ST}}=0.030\right.$; Gapare et al., 2005). However, 18 isozyme markers produced higher polymorphism in total and a higher $F_{\mathrm{ST}}$ in Sitka spruce populations than these STS markers $\left(F_{\mathrm{ST}}=0.063\right.$, recalculated with polymorphic loci; Yeh and El-Kassaby, 1980).

We observed adaptive traits and genetic structure among populations across the entire range of Sitka spruce to understand the mechanisms involved in tree migration and adaptation in response to past environmental change. Sitka spruce is an ideal species for studying these dynamics, because its long, narrow distribution is across a generally linear environmental gradient from south to north along the Pacific coast (Figure 1) simplifying the historical patterns of migration and selection. Our objectives were to: (1) determine the degree of local adaptation to a wide range of environments using a common garden experiment, as well as neutral variation using genetic markers; (2) investigate the implications of gene flow for migration and adaptation.

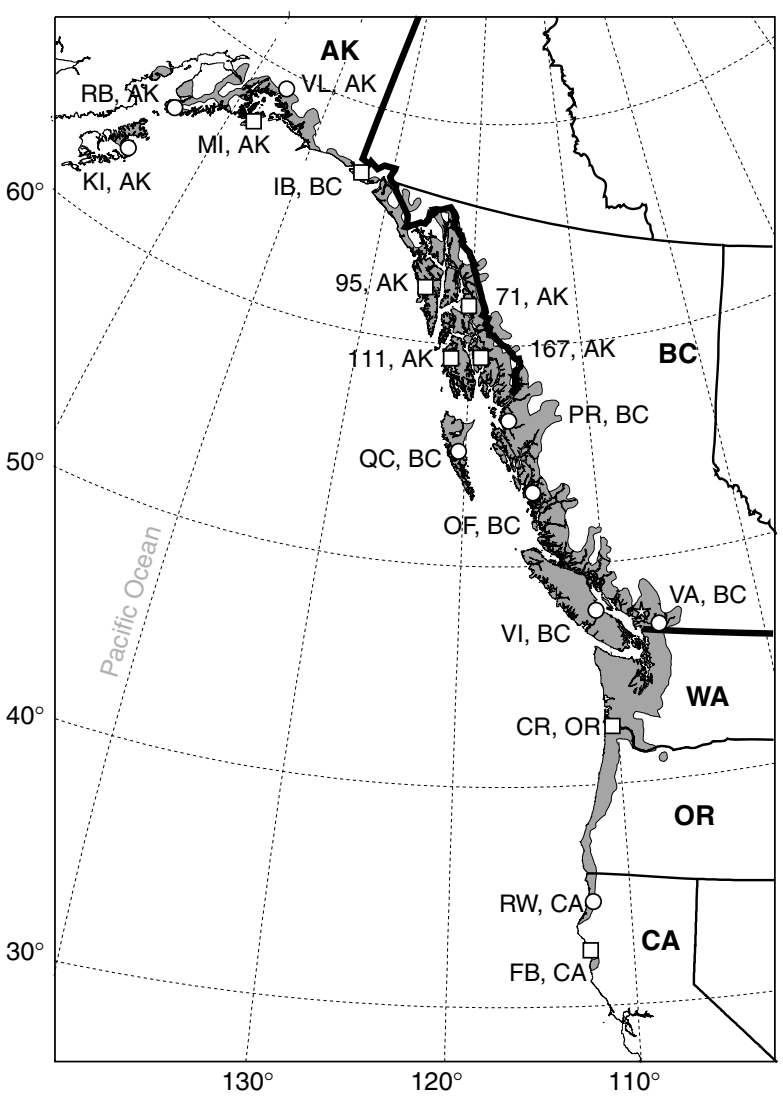

Figure 1 The natural range of $P$. sitchensis and populations sampled. Circles indicate progeny-sampled populations and squares mark bulk populations for quantitative trait analysis. All populations marked were sampled for the common garden experiment. Populations RB and KI from Alaska, PR and OF from British Columbia, and FB and RW from California were also sampled for genetic analysis. The star indicates Vancouver, the location of the common garden experiment.

\section{Materials and methods}

\section{Study area}

Sitka spruce ( $P$. sitchensis) is distributed from Alaska to California along the Pacific Coast of North America where climates are relatively warm and moist (Figure 1). Away from the coast and at higher elevations in the northern portion of the range, forests are dominated by introgression between P. sitchensis and P. glauca (Bennuah et al., 2004). In this study, samples were collected from low elevations $(<70 \mathrm{~m})$ close to the Pacific Ocean to avoid hybrid contamination. Six of the populations sampled for genetic analysis coincide with those used for quantitative trait analysis, while quantitative traits were analyzed for 17 populations in total to test clinal trends and geographic patterns. Seeds were obtained from the British Columbia Ministry of Forests, the University of Alaska, Fairbanks, USDA Forest Service, and California Department of Forestry and Fire Protection, and represented populations from across the full range of the species.

Population genetic structure in pollen gamete pool Two populations from each of the southern range periphery, the center of the distribution and the northern range periphery were selected to assess genetic diversity 
Table 1 Geographic origins and climatic characteristics of populations sampled. Isolation indicates whether populations are located in the continuous (Cont) portion of species' range or are disjunct (Disj), separated from other populations by $60-100 \mathrm{~km}$

\begin{tabular}{|c|c|c|c|c|c|c|c|c|c|c|c|c|}
\hline \multirow[t]{2}{*}{ Population (code) } & \multirow[t]{2}{*}{ State } & \multirow[t]{2}{*}{ Isolation } & \multicolumn{2}{|c|}{ Common garden } & \multicolumn{2}{|c|}{ Marker analysis } & \multicolumn{6}{|c|}{ Geographic and climatic variables } \\
\hline & & & Fam. & Seed & Fam. & Pollen & Dist. & MAT & MWMT & MCMT & $D D$ & $P P$ \\
\hline Valdez (VL) & AK & Cont & 10 & 114 & - & - & 3129 & 3.5 & 12.9 & -5.6 & 815 & 1712 \\
\hline Icy Bay (IB) & AK & Cont & Bulk & 30 & - & - & 2925 & 4.2 & 12.0 & -3.4 & 721 & 4074 \\
\hline Montague (MI) & AK & Cont & Bulk & 30 & - & - & 3272 & 3.9 & 12.5 & -4.1 & 786 & 2445 \\
\hline Rocky Bay (RB) & AK & Cont & 10 & 114 & 19 & 227 & 3540 & 4.1 & 12.7 & -2.2 & 735 & 1706 \\
\hline Kodiak Island (KI) & AK & Disj & 10 & 124 & 20 & 208 & 3693 & 4.7 & 12.8 & -1.3 & 769 & 1914 \\
\hline Lot $71(71)$ & AK & Cont & Bulk & 30 & - & - & 2335 & 7.2 & 14.0 & 1.61 & 1141 & 2188 \\
\hline Lot 95 (95) & $\mathrm{AK}$ & Cont & Bulk & 30 & - & - & 2235 & 5.8 & 14.5 & -3.0 & 1141 & 1628 \\
\hline Lot 167 (167) & AK & Cont & Bulk & 30 & - & - & 2124 & 6.6 & 14.2 & -1.2 & 1184 & 2015 \\
\hline Lot 111 (111) & AK & Cont & Bulk & 30 & - & - & 2080 & 6.6 & 14.0 & -0.1 & 1127 & 2878 \\
\hline Prince Rupert (PR) & $\mathrm{BC}$ & Cont & 12 & 105 & - & - & 1652 & 7.1 & 13.5 & 1.3 & 1226 & 2594 \\
\hline Queen Charlotte Islands (QC) & $\mathrm{BC}$ & Disj & 10 & 87 & 10 & 175 & 1472 & 8.3 & 15.0 & 3.2 & 1462 & 1398 \\
\hline Ocean Falls (OF) & $\mathrm{BC}$ & Cont & 10 & 116 & 18 & 192 & 1429 & 8.0 & 16.8 & -1.0 & 1652 & 1702 \\
\hline Vancouver Island (VI) & $\mathrm{BC}$ & Cont & 11 & 116 & - & - & 1240 & 9.7 & 17.6 & 3.0 & 1960 & 1179 \\
\hline Vancouver (VA) & $\mathrm{BC}$ & Cont & 13 & 121 & - & - & 1099 & 10.0 & 17.1 & 3.6 & 2027 & 1277 \\
\hline Columbia River (CR) & OR & Cont & Bulk & 30 & - & - & 741 & 10.6 & 16.0 & 5.8 & 2019 & 1705 \\
\hline Redwood (RW) & CA & Cont & 10 & 112 & 17 & 192 & 292 & 11.6 & 14.8 & 8.8 & 2395 & 968 \\
\hline Fort Bragg (FB) & CA & Disj & Bulk & 39 & 14 & 196 & 0 & 11.8 & 14.7 & 9.1 & 2479 & 1041 \\
\hline
\end{tabular}

Seedlings (Seed) were nested within open-pollinated families (Fam.) unless indicated as 'Bulk'. Distance (Dist.) indicates the distance in km to the population from southernmost edge of the species range. Pollen indicates the number of seedlings for which the paternal contribution (haplotype) was genotyped. Climatic parameters are mean annual temperature (MAT, $\left.{ }^{\circ} \mathrm{C}\right)$; mean warmest month temperature $\left(\mathrm{MWMT},{ }^{\circ} \mathrm{C}\right)$; mean coldest month temperature (MCMT, ${ }^{\circ} \mathrm{C}$ ); degree days above $5^{\circ} \mathrm{C}(\mathrm{DD})$; and annual precipitation $(\mathrm{PP}, \mathrm{mm})$.

and population genetic structure (Figure 1). For each pair of populations sampled, one was part of the continuous range of Sitka spruce, and one was disjunct, separated by 60-100 km from other populations. Seed was re-collected from two southern peripheral populations in September 2003, while stored seed collections surplus to the needs of the common garden were available for the central and northern populations. Each of six population samples consisted of 7-20 offspring from 10-20 families (Table 1). The pollen gamete contributing to each fertilization producing a seed was determined by genotyping both the embryo (offspring genotype) and corresponding megagametophyte (maternal haplotype). A total of 175-227 pollen gamete haplotypes were determined for each population. As the number of maternal parents sampled was limited, population genetic analysis focused on pollen haplotypes, capturing diversity from more parents in each population. There were no male gamete pool substructures within populations except in the most southern peripheral population (Mimura and Aitken, unpublished data). DNA was extracted from both one-week-old germinants and the corresponding megagametophyte from the seed using the method of Hodgetts et al. (2001). All samples were genotyped for five polymorphic nuclear microsatellite markers: UAPgAG150 developed for P. glauca (Hodgetts et al., 2001), SPAGC1 and SPAGG3 developed for P. abies (Pfeiffer et al., 1997), and WS0073.H08 and WS0061.K02 developed for P. glauca and P. sitchensis (Rungis et al., 2004). Two additional loci, EAC7H07 (Scotti et al., 2002) and UAPgAG105 (Hodgetts et al., 2001), were also genotyped, but were excluded from the analysis due to either low polymorphism (UAPgAG105) or a high frequency of null alleles (EAC7H07).

\section{Common garden experiments}

Seedlings in the common garden experiment originated from 17 populations (Table 1). Nine of these were represented by open-pollinated progeny of 10-13 seed parents for each population. Montague Island (MI, AK), Icy Bay (IB, AK) and Columbia River (CR, OR) were bulked to average 30.6 individuals from 12.3 families per population. The remaining eight populations were represented by bulk wild-stand open-pollinated seedlots for reforestation for which seeds were not identified by mother tree (Figure 1). Bulk seedlots collected for reforestation comprised seed from at least 10 seed parents, usually many more.

Seeds were germinated in 2002 on filter paper in petri dishes at room temperature after soaking in water for $48 \mathrm{~h}$ and stratifying for 3 weeks at $4{ }^{\circ} \mathrm{C}$. Germinants were transplanted into Super Leach Tubes and grown in a greenhouse at University of British Columbia in Vancouver, BC, for one growing season. In February 2003, the seedlings were transplanted into outdoor raised nursery beds at UBC. The beds were $0.75 \mathrm{~m}$ tall and filled with a well-drained sandy loam topsoil. Since the southern and northern populations exhibited considerable differences in height in the first year, populations were grouped into southern, central and northern regions to avoid shading effects. A split-plot block design was used with eight blocks, where the main plots were regions and the subplots were populations within region. Population subplots were noncontiguous with individuals from populations randomized within main plots. Bud phenology (timing of bud break and bud set) and height were recorded repeatedly throughout the growing period in 2003. Final height was also obtained at the end of the growing season in 2004. Bud break was defined as the Julian date when needle primordia first emerged though the bud scales. Bud set was defined as the Julian date when brown bud scales were first visible to the naked eye at the leader shoot apex. To eliminate first year effects, height in the second and third year was recorded as the length between first year or second year terminal bud scale scars and the shoot apex. 


\section{Cold hardiness test}

Cold hardiness was determined by artificial freeze testing on a subset of trees after bud set in the fall of 2003 using the methods described in Hannerz et al. (1999). One or more branches were harvested, and four needle segments $5 \mathrm{~mm}$ in length cut at both ends were placed in each tube with $0.2 \mathrm{ml}$ of distilled water and a trace of silver iodide for ice nucleation. A total of 446 individuals from 17 populations were sampled on November 3, and 420 individuals from 17 populations sampled on November 10. For the samples harvested on November 3, the test temperatures were -16 and $-26^{\circ} \mathrm{C}$, and for the samples harvested on November 10 , they were -20 and $-30^{\circ} \mathrm{C}$ due to anticipated acclimation between the two sample dates. At the planting site in Vancouver, the first natural frost occurred during the week of November 3, 2003. Increased cold hardiness generally develops after the first exposure to frost (Sakai and Larcher, 1987). Thus, we lowered the test temperature for the second week of testing (November 10). For both test dates, chamber temperature was lowered at a rate of $4^{\circ} \mathrm{C} / \mathrm{h}$ from an initial temperature of $4^{\circ} \mathrm{C}$, and held at the first test temperature for one $1 \mathrm{~h}$. One complete set of samples was then removed, and the temperature was further decreased by $4{ }^{\circ} \mathrm{C} / \mathrm{h}$ to the second test temperature, and again held for $1 \mathrm{~h}$ before the second complete set was removed. Control samples for all genotypes were kept at $4{ }^{\circ} \mathrm{C}$ for the duration of freezing. After freezing, samples were thawed overnight at $4{ }^{\circ} \mathrm{C}$, diluted with $3 \mathrm{ml}$ of distilled water, shaken for $1 \mathrm{~h}$ and measured for electrolytic conductivity. Samples were then heat killed in $95^{\circ} \mathrm{C}$ water bath, shaken for $1 \mathrm{~h}$ and remeasured for maximum conductivity. Flint's Index of Injury (cold injury index) was estimated as a percent of maximum injury possible from the electrolytic leakage of the corresponding control, frozen and heatkilled samples (Hannerz et al., 1999).

\section{Data analyses}

Genetic data: Allele frequencies of pollen gamete pools for each population were calculated using Arlequin Version 2.001 (Schneider et al., 2000). Two statistical measures of genetic distances, $F_{\mathrm{ST}}$ (Wright, 1951) and $R_{\mathrm{ST}}$ (Slatkin, 1995), were estimated from components of genetic variation within and among population, and for pollen gamete haplotypes pooled within populations, also using Arlequin v. 2.001. $F_{\mathrm{ST}}$ is an estimate of the genetic distance derived from variation in allele frequencies among populations based on the infinite allele model. $R_{\mathrm{ST}}$ is an analog of $F_{\mathrm{ST}}$, developed specifically for microsatellite markers that follow the stepwise mutation model (SMM), and takes into account allele size. $R_{\mathrm{ST}}$ is generally recognized as a better estimator when mutation rate is high relative to migration rate, while $F_{\mathrm{ST}}$ is a conservative estimate under most conditions if sample size is small (Gaggiotti et al., 1999). In this study, both estimators were used to analyze effects of genetic drift and mutation on population structure. The correlation between genetic and geographic distance matrices was tested using a Mantel test with 1000 permutations with genetic distance expressed as $F_{\mathrm{ST}} /\left(1-F_{\mathrm{ST}}\right)$ or $R_{\mathrm{ST}} /\left(1-R_{\mathrm{ST}}\right)$ following Rousset (1997).

\section{Quantitative growth trait data}

Height measurements were log-transformed to generate a more normal distribution. To understand patterns of variation in growth traits across the geographic range, analyses of variance were calculated for second and third year height, bud break, bud set, growth period (days between date of bud break and date of bud set), mean daily growth rate (height increment divided by growth period) and cold injury index, using the model;

$$
y_{i j l}=u+b_{i}+p_{j}+f(p)_{j k}+b_{i} \times p_{j}
$$

where $b$ is the effect of block $i, p_{j}$ is the effect of population $j$ and $f(p)_{j k}$ is the effect of family $k$ within population $j$. The regional plots in the experimental design to avoid shading effects were not included in this model to allow for quantification of clinal pattern rangewide and their association with environmental gradients. Preliminary analyses indicated continuous clinal patterns in population means across the regional groupings. Cold injury index for the freezing tests on the two different dates were highly correlated phenotypically $(r=0.96)$, thus cold hardiness scores from each date were standardized, combined and analyzed as a single trait. Least squared population means were estimated with this model using PROC GLM in SAS Version 9.0 (SAS Institute Inc., 2000). The procedure estimated simple linear regression coefficients of population means with distance along the coast as an independent variable. Correlations among traits were estimated for population means using PROC CORR.

Principal component analysis was applied to quantitative data for population means for all variables using PROC PRINCOMP. Principal component analysis extracts orthogonal variables that are linear combinations of the original variables best explaining the total variance in the data set. Using PROC REG, multiple regressions were then performed on the first two principal component scores as dependent variables with geographical and climatic factors (distance along the coast, mean annual temperature, mean warmest month temperature, mean coldest month temperature, growing degree days (above $5^{\circ} \mathrm{C}$ ) and precipitation) (Table 1) as independent variables. Principal components were included in regression models when their eigenvalues were greater than 1.0.

We compared standardized measures of genetic differentiation for neutral genetic markers ( $F_{\mathrm{ST}}$ and $\left.R_{\mathrm{ST}}\right)$ with quantitative traits $\left(Q_{\mathrm{ST}}\right)$ to evaluate the relative strengths of natural selection and genetic drift on population differentiation (Merilä and Crnokrak, 2001). One of the six populations (Fort Bragg, FB) used for estimating population genetic structure was represented by bulk seedlot samples in the common garden experiment (Table 1). $Q_{\mathrm{ST}}$ was estimated for the five remaining populations, following Spitze (1993) for family-structured populations from additive genetic variances estimated using the PROC VARCOMP procedure of SAS with the restricted maximum likelihood option $(\mathrm{METHOD}=\mathrm{REML})$. The additive genetic variances for each trait were also used to estimate within population individual heritabilities.

\section{Results}

Allelic richness was highest in central and lower in peripheral populations (Table 2). There were also more private alleles in the central and continuous populations (Table 2 and Supplementary Table 1). Gene diversity was 
higher in the central populations and lowest in the isolated peripheral populations.

The genetic distance measures $F_{\mathrm{ST}}$ and $R_{\mathrm{ST}}$ showed similar degrees of population differentiation (Table 3, $F_{\mathrm{ST}}=0.11, R_{\mathrm{ST}}=0.09$ ). For both measures of genetic distance, the two central populations, regardless of degree of isolation, are core in terms of genetic structure. Correlations of geographic and genetic distances between populations were statistically significant (Figure 2). IBD was stronger for $R_{\mathrm{ST}}$ (Mantel test: $r=0.72, P=0.003$ ) than for $F_{\mathrm{ST}}$ (Mantel test: $r=0.51, P=0.051$ ).

Individual heritabilities were moderate and fairly uniform across quantitative traits, ranging from 0.17-0.32 (Table 4). Bud break timing had the lowest heritability among the observed traits and bud set timing had the highest. Height at age 3 had a lower estimated heritability but higher $Q_{\mathrm{ST}}$ value than height at age 2 .

Regressions of quantitative traits with distance along the coast revealed strong, significant clines for all traits except bud break timing (Table 4). Southern populations had much longer periods of primary growth than northern populations. Height, days to bud set and fall cold injury significantly increased toward the south, while average daily growth rate increased significantly to the north. The log of height increment (height) at age 2 (2003) and 3 (2004) increased at a rate of 0.023 per $100 \mathrm{~km}$ south. Julian days to bud set increased by 3.2 days, and standardized cold injury index increased by $7 \%$ for every $100 \mathrm{~km}$ south. Mean daily growth rate (growth rate) decreased $0.008 \mathrm{~mm}$ per day for every $100 \mathrm{~km}$ south. Bud break timing and daily growth rate appeared to be genetically independent traits (Table 5). In contrast, significant negative phenotypic correlations were found between population mean growth rate and bud set timing $(r=-0.56)$, and between growth rate and growth period (days from bud break to bud set; $r=-0.58$ ). This means individuals that terminate primary growth earlier (set buds earlier) tend to grow faster within the limited growing periods. Overall, populations from the north set bud earlier, grew less overall in height but more per day, and were hardier to cold events in fall than southern populations.

Principal component analysis of population mean quantitative growth traits revealed strong geographic and climatic relationships (Figure 3 and Supplementary Figure S1). Principal component 1 (PC1) represented $72.2 \%$ of the overall variation in growth (height at age 2 and 3 , bud break timing at age 2, bud set timing at age 2 and average fall cold injury index week 1 and week 2) (Supplementary Table S2). PC2 primarily represented daily growth rate and bud break timing, and accounted for $17.9 \%$ of the total variation). Regression analyses were performed on the first two principal components (PC1 and PC2) whose eigenvalues were more than 1.0. PC1 had a significant linear relationship with distance along the coast, MAT (Figure 3a), mean warmest month temperature (MWMT), mean coldest month temperature (MCMT) and growing degree days (DD) (Supplementary Table S3). PC2 had a significant relationship only with MWMT $(P=0.04$; Figure 3b). Unlike other climate variables, MWMT does not show a linear relationship with latitude. It is higher in the south-central Vancouver area (latitude $49.16^{\circ}$ ) and lower at the northern and southern range margins, inverse to the U-shaped northsouth distribution of PC2.

Table 2 Diversity statistics for the five microsatellite loci used in genotyping samples

\begin{tabular}{|c|c|c|c|c|c|c|}
\hline & \multicolumn{2}{|c|}{ North } & \multicolumn{2}{|c|}{ Central } & \multicolumn{2}{|c|}{ South } \\
\hline & $\begin{array}{c}\text { Cont } \\
\mathrm{n}=227\end{array}$ & $\begin{array}{c}\text { Disj } \\
\mathrm{n}=208\end{array}$ & $\begin{array}{c}\text { Cont } \\
\mathrm{n}=192\end{array}$ & $\begin{array}{c}\text { Disj } \\
\mathrm{n}=175\end{array}$ & $\begin{array}{c}\text { Cont } \\
\mathrm{n}=192\end{array}$ & $\begin{array}{c}\text { Disj } \\
\mathrm{n}=196\end{array}$ \\
\hline Total number of alleles (of 61 total) ${ }^{\mathrm{a}}$ & 34.0 & 28.6 & 45.4 & 49.8 & 43.3 & 29.3 \\
\hline Average number of alleles per locus $\mathrm{a}^{\mathrm{a}}$ & 6.8 & 5.7 & 9.1 & 10.0 & 8.7 & 5.9 \\
\hline Private alleles ${ }^{\mathrm{a}, \mathrm{b}}$ & 3.5 & 0.0 & 3.1 & 4.5 & 4.1 & 1.0 \\
\hline Gene diversity $\left(\mathrm{H}_{\mathrm{ge}}\right)^{c}$ & $0.65(0.08)$ & $0.57(0.11)$ & $0.75(0.05)$ & $0.75(0.05)$ & $0.72(0.08)$ & $0.63(0.09)$ \\
\hline
\end{tabular}

Abbreviations: Cont, continuous; Disj, disjunct.

Pollen gamete haplotypes were pooled within populations, and averaged over the five loci. Private alleles are calculated as the weighted number of alleles that occurred only in one of the populations sampled.

${ }^{a}$ All observed number of alleles were weighted by average sample size $(n=198)$.

${ }^{\mathrm{b}}$ Weighted number of alleles that were only observed in one population.

${ }^{\mathrm{c}}$ Gene diversity was estimated as $1-\Sigma p_{i}^{2}$ where $p_{i}$ is frequency of allele $i$ at a locus, then averaged over loci.

Table 3 Pairwise genetic distances between populations sampled. $F_{\mathrm{ST}}$ estimates are above the diagonal and $R_{\mathrm{ST}}$ estimates are below the diagonal in italics

\begin{tabular}{|c|c|c|c|c|c|c|c|c|}
\hline \multirow[t]{2}{*}{ Region } & \multirow[t]{2}{*}{ Isolation } & \multirow[t]{2}{*}{ Population } & \multicolumn{2}{|c|}{ South } & \multicolumn{2}{|c|}{ Central } & \multicolumn{2}{|c|}{ North } \\
\hline & & & $\begin{array}{c}\text { Continuous } \\
R W, C A\end{array}$ & $\begin{array}{l}\text { Disjunct } \\
F B, C A\end{array}$ & $\begin{array}{c}\text { Continuous } \\
\text { OF, BC }\end{array}$ & $\begin{array}{l}\text { Disjunct } \\
Q C, B C\end{array}$ & $\begin{array}{l}\text { Continuous } \\
R B, A K\end{array}$ & $\begin{array}{c}\text { Disjunct } \\
\text { KI, AK }\end{array}$ \\
\hline \multirow[t]{2}{*}{ South } & Continuous & RW, CA & & 0.06 & 0.03 & 0.03 & 0.05 & 0.14 \\
\hline & Disjunct & $\mathrm{FB}, \mathrm{CA}$ & 0.00 & & 0.13 & 0.12 & 0.14 & 0.24 \\
\hline \multirow[t]{2}{*}{ Central } & Continuous & OF, BC & 0.02 & 0.06 & & 0.00 & 0.10 & 0.16 \\
\hline & Disjunct & $\mathrm{QC}, \mathrm{BC}$ & 0.01 & 0.03 & 0.00 & & 0.10 & 0.15 \\
\hline \multirow[t]{2}{*}{ North } & Continuous & RB, AK & 0.17 & 0.23 & 0.09 & 0.12 & & 0.17 \\
\hline & Disjunct & KI, AK & 0.19 & 0.21 & 0.17 & 0.17 & 0.19 & \\
\hline
\end{tabular}



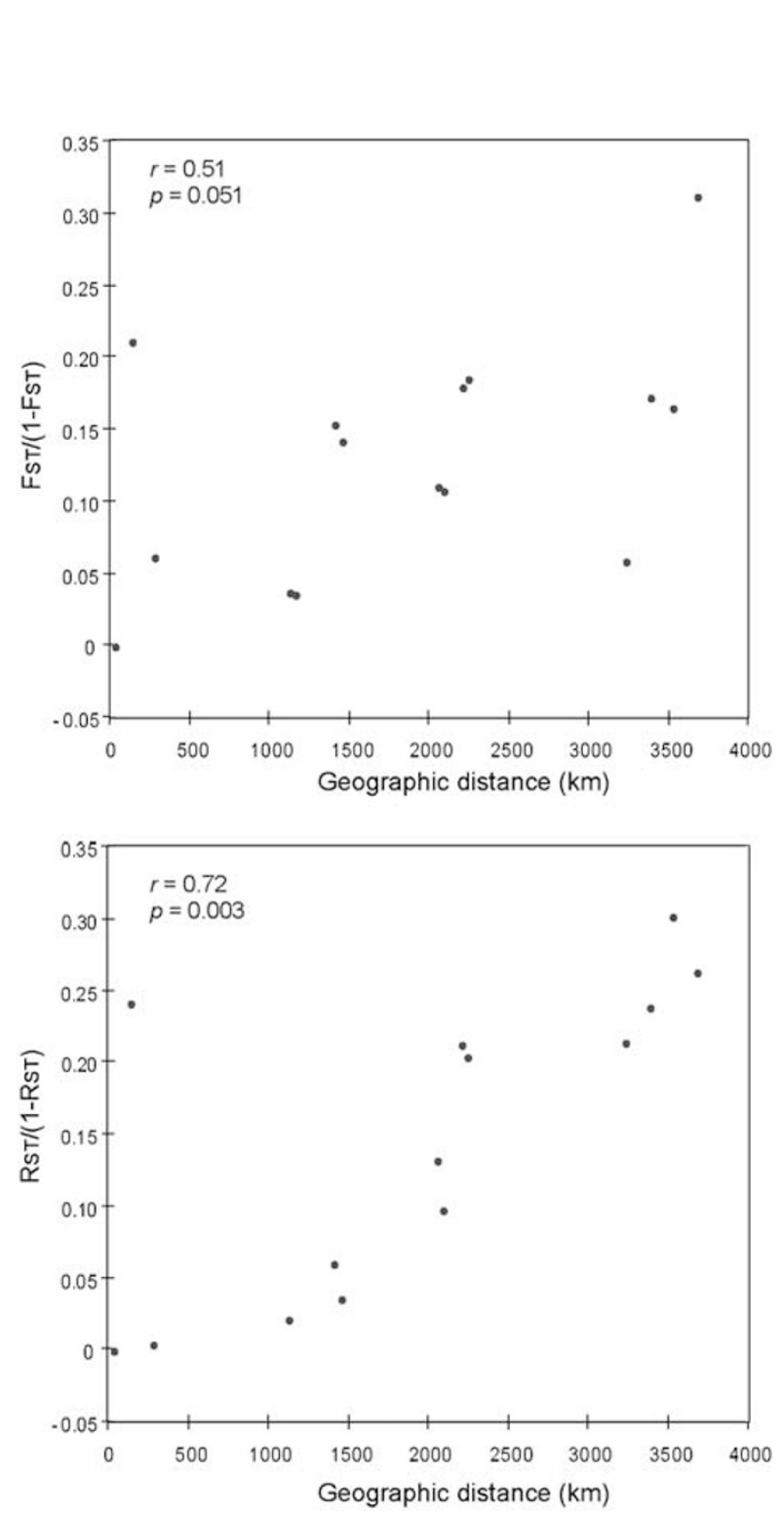

Figure 2 Geographic distance versus genetic distance among populations for $F_{\mathrm{ST}}$ and $R_{\mathrm{ST}}$. Correlations and probabilities were estimated from a Mantel test with 1000 repeats of bootstrap resampling. The $y$-axis is $F_{\mathrm{ST}} /\left(1-F_{\mathrm{ST}}\right)$ (or $\left.R_{\mathrm{ST}} /\left(1-R_{\mathrm{ST}}\right)\right)$ following Rousset (1997).
Mean population differentiation for the observed growth traits $\left(Q_{\mathrm{ST}}\right)$ was 0.61 (Table 4$)$. Cold injury index, bud set timing and growth period exhibited extremely strong differentiation among populations $\left(Q_{\mathrm{ST}}=0.89\right.$, 0.89 and 0.87, respectively) and these traits were highly correlated (Table 5). Daily growth rate showed lower but still substantial population differentiation $\left(Q_{\mathrm{ST}}=0.28\right)$. Height at age 3 showed stronger differentiation among populations than at age 2. All $Q_{\mathrm{ST}}$ estimates were based on only the five populations represented by open-pollinated families in the common garden and genotyped for microsatellite markers as they allowed estimation of additive genetic variance within populations and comparisons with population differentiation for markers. All $Q_{\mathrm{ST}}$ estimates were substantially higher than estimates of population differentiation for the neutral genetic markers, $F_{\mathrm{ST}}$ and $R_{\mathrm{ST}}$ (Tables 3 and 4).

\section{Discussion}

\section{Adaptive divergence across the range}

Clines in growth traits of Sitka spruce with latitude have long been recognized (Harris, 1978; Xu et al., 2000). Strong geographic clines in all quantitative traits except bud break timing were also observed in this study, and strong differences in population adaptation to local environments have been characterized. For example, individuals from southern populations grow taller than those from northern populations, while individuals from the north grow faster per day than those from southern populations. These growth strategies correspond to available frost-free growing periods in the original environments of these populations. The date with a $50 \%$ probability of first frost $\left(0^{\circ} \mathrm{C}\right)$ occurs on or before September 30 in Kodiak Island and Kitoi Island, AK (Western Regional Climate Centre, USA), but not until December 16 in Fort Bragg, CA (Koss et al., 1988). The growth response in the northern populations appears to be an adaptive strategy well suited to a short growing season and low-temperature environment: reach maximum growth as quickly as possible within the limited favorable period, while minimizing the risk

Table 4 Among-population variation and north-south clines in growth traits. Heritability and $\mathrm{Q}_{\mathrm{ST}}$ estimates are based on 5 of the same 6 populations used for the neutral variation study (Table 3)

\begin{tabular}{|c|c|c|c|c|c|}
\hline \multirow[t]{2}{*}{ Growth traits } & \multirow[t]{2}{*}{ Heritability } & \multirow[t]{2}{*}{$Q_{S T}$} & \multicolumn{3}{|c|}{ North-south cline *a } \\
\hline & & & $\mathrm{R}^{2}$ & $\mathrm{P}$ & Change per $100 \mathrm{~km}$ \\
\hline Height age $2^{\mathrm{b}}$ & 0.32 & 0.55 & 0.24 & $<0.0001$ & 0.023 \\
\hline Height age $3^{\mathrm{b}}$ & 0.26 & 0.79 & 0.48 & $<0.0001$ & 0.023 \\
\hline Bud break (days) ${ }^{c}$ & 0.17 & 0.29 & 0.05 & 0.3864 & 0.06 \\
\hline Bud set (days) ${ }^{c}$ & 0.32 & 0.89 & 0.94 & $<0.0001$ & 3.24 \\
\hline Growth period (days) & 0.31 & 0.87 & 0.71 & $<0.0001$ & 3.00 \\
\hline Growth rate $(\mathrm{mm})^{\mathrm{d}}$ & 0.24 & 0.28 & 0.39 & 0.0073 & -0.008 \\
\hline Cold injury index ${ }^{\mathrm{e}}$ & 0.30 & 0.89 & 0.58 & $<0.0001$ & 0.07 \\
\hline
\end{tabular}

The five populations include RB, KI, OF, QC, and RW. The change in all traits per $100 \mathrm{~km}$ along the Pacific Coast of North America from north to south is estimated based on all 17 populations. Significant regressions $(P<0.05)$ are indicated in bold.

${ }^{a}$ Change in trait per $100 \mathrm{~km}$ to the south.

${ }^{\mathrm{b}} \mathrm{Log}$ transformed.

'Julian date (days from Jan. 1st).

${ }^{\mathrm{d}}$ Mean daily growth $=$ (height at age 2 )/(bud set Julian date - bud break Julian date).

eAnalyzed as standardized cold injury index of the freezing tests on the two dates. 
Table 5 Pearson correlations among population means for quantitative traits measured in 17 Sitka spruce populations in a common garden

\begin{tabular}{lccccccc}
\hline & $\begin{array}{c}\text { Height } \\
\text { age 2 }\end{array}$ & $\begin{array}{c}\text { Height } \\
\text { age 3 }\end{array}$ & $\begin{array}{c}\text { Bud } \\
\text { set }\end{array}$ & $\begin{array}{c}\text { Bud } \\
\text { break }\end{array}$ & $\begin{array}{c}\text { Growth } \\
\text { period }\end{array}$ & $\begin{array}{c}\text { Growth } \\
\text { rate }\end{array}$ & $\begin{array}{c}\text { Cold } \\
\text { injury } \\
\text { index }\end{array}$ \\
\hline Height age 2 $^{\mathrm{a}}$ & 1 & $\mathbf{0 . 8 5}$ & $\mathbf{0 . 9 0}$ & 0.30 & $\mathbf{0 . 9 0}$ & -0.18 & $\mathbf{0 . 9 4}$ \\
Height age 3 $^{\mathrm{a}}$ & & 1 & $\mathbf{0 . 9 5}$ & 0.3 & $\mathbf{0 . 9 4}$ & $-\mathbf{0 . 5 6}$ & $\mathbf{0 . 9 2}$ \\
Bud set & & & 1 & 0.25 & $\mathbf{0 . 9 9}$ & $-\mathbf{0 . 5 6}$ & $\mathbf{0 . 9 4}$ \\
Bud break & & & & 1 & 0.18 & 0.16 & 0.44 \\
Growth period & & & & & 1 & $-\mathbf{0 . 5 8}$ & $\mathbf{0 . 9 2}$ \\
Growth rate & & & & & & 1 & -0.35 \\
Cold injury index & & & & & & 1 \\
\hline
\end{tabular}

Significant correlations $(P<0.05)$ are indicated in bold. ${ }^{\text {a }}$ og transformed.

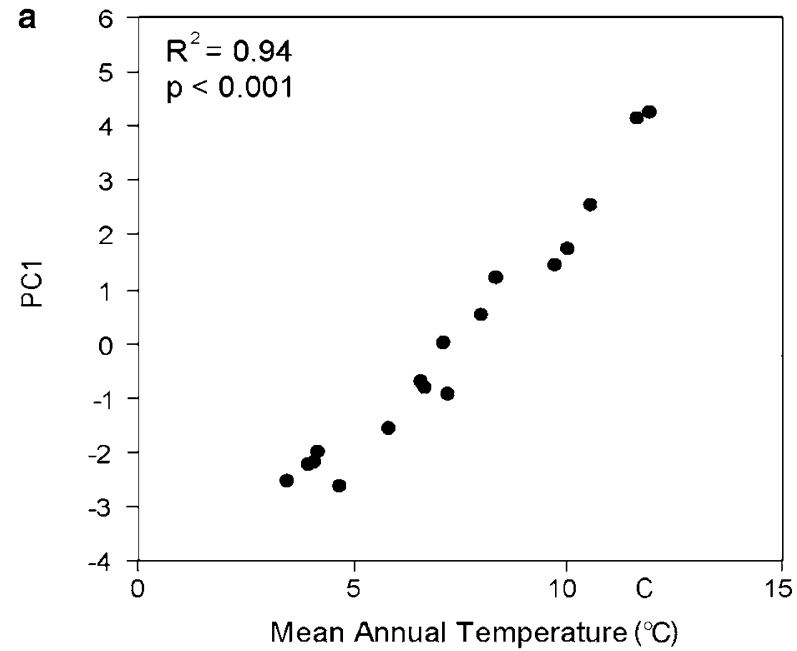

b

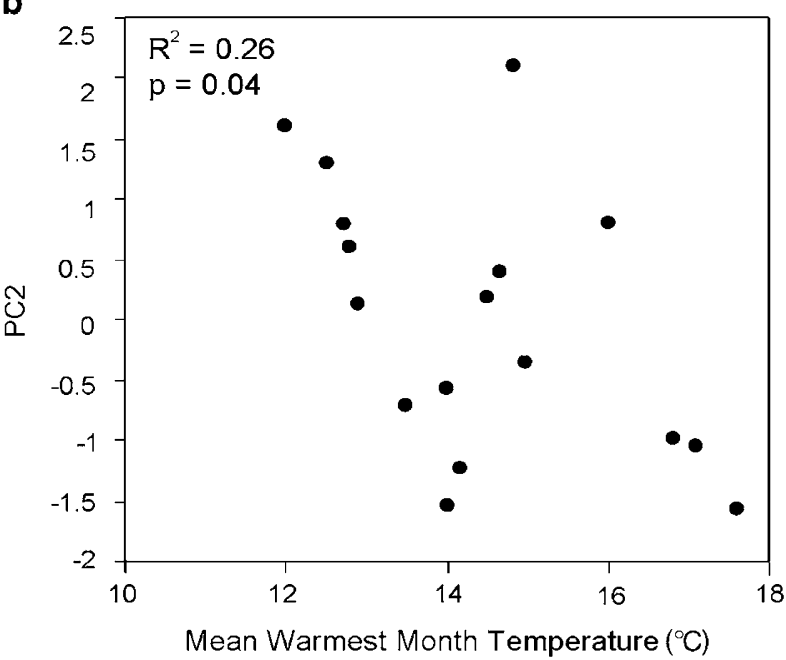

Figure 3 Regression analysis of the first two principal components (PC1 and PC2) for quantitative traits on climatic variables in Table 1.

of cold injury. Summer temperature of population source environments is an indirect indicator of growth rate and timing of bud break, where lower summer temperatures are associated with later bud break but faster subsequent growth rate (Supplementary Table 3). All traits we observed are assumed to be under differential selection for local adaptation as all $Q_{\mathrm{ST}}$ estimates exceeded estimates of neutral genetic distance $F_{\mathrm{ST}}$ and $R_{\mathrm{ST}}$ (Merilä and Crnokrak, 2001).

Synchronization of bud phenology to local climates is key for the adaptation of conifers (Howe et al., 2003), as fall and spring frosts can severely damage current year shoot and needles (Redfern and Cannell (1982); Peterson et al., 1997). Before hardening, or when dehardening occurs during warm periods in winter, tissues become more susceptible to frost (Cannell et al., 1985), thus cold hardiness is an adaptive trait for optimal growth (Howe et al., 2003). For conifer species, bud set timing is generally determined by photoperiod (critical night length) and bud break by heat sum accumulation in spring following adequate chilling in winter (Sakai and Larcher, 1987). In this study, bud set timing was strongly correlated with growth period and cold injury index, while there was no significant clinal variation in bud break timing exhibited among populations in a common environment. This indicates that populations likely do not differ much in chilling requirements to overcome bud dormancy or heat sum requirements to initiate bud break after dormancy is broken, or that there is compensatory variation between these requirements. Therefore, although both bud set and bud break phenology are major determinants of seasonal growth cycle in Sitka spruce, bud set timing (which shows different critical photoperiods among populations for initiation) appears more important when populations are migrating or when environments are changing. Cold hardiness is highest in northern populations, and has a very high $Q_{\mathrm{ST}}$ estimate and a strong clinal relationship with geographic distances (Table 4). The southernmost populations showed little, if any, development of cold hardiness. Hardiness would probably be less beneficial in the California environment where temperatures rarely drop down below $0^{\circ} \mathrm{C}$ throughout year (average minimum temperature of the coldest month $4.4^{\circ} \mathrm{C}$ at Fort Bragg, Normal Climate Data, 1971-2000, National Climate Data Center of US). The steep cline observed for bud set timing and cold hardiness is evidence for differential adaptation to the risk of frost.

\section{Isolation-by-distance in recently migrated populations}

The microsatellite markers used detected relatively strong genetic differentiation among populations of Sitka spruce $\left(F_{\mathrm{ST}}=0.11 ; R_{\mathrm{ST}}=0.09\right)$. Conifers generally have low genetic differentiation for nuclear loci, for instance $G_{\text {ST }}$ averages 0.055 in Picea, 0.065 in Pinus and 0.063 in Abies (Hamrick et al., 1992; Le Corre and Kremer, 1998). The weak genetic differentiation of conifer populations is usually attributed to high gene flow $(\mathrm{Nm}>1)$ via winddispersed pollen, as well as large effective population sizes, preventing differentiation due to genetic drift (Hamrick et al., 1992). In this study, the genetic differentiation detected by microsatellites for six pollen gamete population pools was much higher than that found for eight populations from the same geographic range (Fort Bragg, CA to Kodiak Island, AK) with a large sample of mature trees genotyped using eight STS markers $\left(F_{\mathrm{ST}}=0.03\right.$, Gapare et al., 2005). This does not agree with a general expectation: a high stepwise mutation rate on microsatellite loci could decrease $F_{\mathrm{ST}}$ either by increasing homoplasy (Balloux and LugonMoulin, 2002) or increasing within-population variation 
(Hedrick, 1999). The eight STS loci average 3.25 alleles per locus, while in the current study, the five loci averaged 12.2 alleles per locus. The STS markers were developed based on EST sites and reflect mostly intronlength polymorphisms (Perry and Bousquet, 1998a, b), which may result in a low level of polymorphism. Our estimate is relatively similar to the isozyme-based estimate for 10 populations from a slightly smaller geographic range $\left(F_{\mathrm{ST}}=0.063\right.$, recalculated with 18 polymorphic loci from allele frequencies in Yeh and El-Kassaby, 1980). The difference between the STS and microsatellite markers may also simply reflect the variance of these estimates.

Our estimates of $F_{\mathrm{ST}}$ and $R_{\mathrm{ST}}$ among all populations were similar, on average, but pairwise comparisons between populations illustrated differences between these estimates. $F_{\mathrm{ST}}$, assuming mutation follows the infinite alleles model, can provide a measurement of population differentiation caused by genetic drift (Reynolds et al., 1983), yet a primary problem of $F_{\mathrm{ST}}$ is its sensitivity to mutation rate when gene flow is low (Balloux and Lugon-Moulin, 2002). Based on the high levels of polymorphism observed, it is assumed that the microsatellite mutation rate is generally high, and that mutations mostly follow the SMM. $R_{\mathrm{ST}}$ takes into account differences in the number of motif repeats in microsatellite alleles resulting from such stepwise mutations (Slatkin, 1995). Under the strict SMM, $R_{\mathrm{ST}}$ is independent of the mutation rate. Balloux and Lugon-Moulin (2002) noted that the factor influencing measurements of $F_{\mathrm{ST}}$ and $R_{\mathrm{ST}}$ is not mutation rate itself, but the magnitude of mutation relative to gene flow and mutation has little influence on the measurement of $F_{\mathrm{ST}}$ and $\mathrm{R}_{\mathrm{ST}}$ when gene flow is high. Therefore, the values of these two measurements should become more similar as relative migration rate increases. The stronger IBD pattern revealed by pairwise $R_{\mathrm{ST}}$ estimates compared to $F_{\mathrm{ST}}$ may suggest that recent gene flow is relatively limited among populations and $R_{\mathrm{ST}}$ better reflects the effect of this gene flow on population structure than $F_{\mathrm{ST}}$ in this species with microsatellite loci.

IBD should be more pronounced at equilibrium, and it may take populations considerable time to achieve this state (Slatkin, 1993). High-dispersal insect species also tend to show weak IBD (Peterson and Denno, 1998). Strong IBD may not develop in Sitka spruce due to: (1) long-distance dispersal via pollen inhibiting population divergence; or (2) the great northward range expansion that occurred since the last glacial maximum $(<15000$ years ago). The genetic diversity in these populations may not have always decreased toward the north (the migration tips); this pattern may have resulted from current isolation associated with current population size and other historical reductions in population size. Despite the species' rapid expansion and loss of alleles in isolated populations, moderate IBD in this species suggests that the populations can to some extent reach drift-migration equilibrium fairly quickly, at least at microsatellite loci, and that the majority of contemporary gene flow is restricted to within geographic regions, showing a stepping stone pattern of migration along the coastal distribution of the range. Wright (1946) showed that IBD should occur over shorter distances in species with linear distributions than in species with nonlinear distributions. The generally linear distribution of Sitka spruce on the coastal line may contribute to the IBD and genetic structure. IBD may suggest the accumulation of genetic differentiation with time since divergence from a single ancestral population; however, we genotyped too few populations to identify putative refugia in this study. We conclude that gene flow within geographic regions has been an important factor influencing current population structure, despite possible long-distance dispersal during past migration.

Considering that rapid past migrations of tree species cannot be explained without invoking long-distance dispersal, yet gene flow from neighboring rather than distant populations is crucial for adaptation, we hypothesize adaptation occurred in conjunction with postglacial migration. In the first phase of postglacial migration, long-distance dispersal of seed may have initially established populations, followed by pollen flow from neighboring populations that increased genetic diversity within these new populations. In this phase, the effective population size of the founder population would increase, while hard selection (for example frost events) would act on traits essential for survival (for example bud set timing). Selection is more efficient in larger and more variable populations. Following population establishment, soft selection would increase the frequency of locally favored alleles associated with more competitive growth, which perhaps would originate from neighboring rather than distant populations. Ultimately, this results in geographic clines. This occurs when environmental gradients are steep enough for selection to counteract gene flow. Conifer species such as Sitka spruce, with wind pollination, high fecundity, high longevity and high gene flow, may have effective population sizes that are closer to census size than species with other life history traits. This gives Sitka spruce the ability to colonize new areas and sustain founder populations until population size and withinpopulation variation reach sustainable levels that can respond to selection efficiently. Through these processes, wind-pollinated conifers have had the capacity to adapt to rapid environment changes in the past. However, it should be noted that Mimura and Aitken (in press) found that contemporary mating system was strongly influenced by geographic position, potentially associated with population size. It appears that effective population size, outcrossing rate and effective number of pollen donors all decline toward the northern and southern range peripheries, especially in the disjunct peripheral populations. This is also suggestive of the sensitivity of the species to current population size and gene flow.

Sitka spruce exhibits a wide range of adaptive trait variation despite rapid Quaternary migration, and has maintained or recovered relatively strong population genetic structure in the past 15000 years. Gene flow could be partially responsible for the rapid migration capacity of Sitka spruce by providing diversity for more effective adaptation to new environments encountered during migration, although current gene flow appears relatively limited, possibly contributing to the maintenance of adaptive divergence. The degree of adaptation may depend on rates of gene flow and the steepness of environmental gradients. This tree species has demonstrated a high capacity to respond to selection and adapt to past climate change along the Pacific Coast of North America. 


\section{References}

Balloux F, Lugon-Moulin N (2002). The estimation of population differentiation with microsatellite markers. Mol Ecol 11: 155-165.

Bennuah SY, Wang TL, Aitken SN (2004). Genetic analysis of the Picea sitchensis $\times$ glauca introgression zone in British Columbia. For Ecol Manage 197: 65-77.

Campbell RK (1979). Genecology of Douglas-fir in a watershed in the Oregon Cascades. Ecology 60: 1036-1050.

Cannell MGR, Sheppard LJ, Smith R, Murray MB (1985). Autumn frost damage on young Picea sitchensis. 2. Shoot frost hardening, and the probability of frost damage in Scotland Forestry 58: 145-166.

Clark JS (1998). Why trees migrate so fast: confronting theory with dispersal biology and the paleorecord. Am Nat 152: 204-224.

Clark JS, Lewis M, McLachlan JS, HilleRisLambers J (2003). Estimating population spread: what can we forecast and how well? Ecology 84: 1979-1988.

Daubenmire R (1967). Some geographic variations in Picea sitchensis and their ecologic interpretation. Can J Bot 46: 787-798.

Davis MB (1981). Quaternary history and the stability of forest communities. In: West DC, Shugart HH, Botkin DB (eds). Forest Succession: Concepts and Application. Springer: New York.

Davis MB, Shaw RG (2001). Range shifts and adaptive responses to Quaternary climate change. Science 292: 673-679.

Gaggiotti OE, Lange O, Rassmann K, Gliddon C (1999). A comparison of two indirect methods for estimating average levels of gene flow using microsatellite data. Mol Ecol 8: 1513-1520.

Gapare WJ, Aitken SN, Ritland CE (2005). Genetic diversity of core and peripheral Sitka spruce (Picea sitchensis (Bong Carr)) populations: implications for conservation of widespread species. Biol Conserv 123: 113-123.

Genton BJ, Shykoff JA, Giraud T (2005). High genetic diversity in French invasive populations of common ragweed, Ambrosia artemisiifolia, as a result of multiple sources of introduction. Mol Ecol 14: 4275-4285.

Hamrick JL, Godt MJW, Sherman-Broyles SL (1992). Factors influencing levels of genetic diversity in woody plant species. New Forest 6: 95-124.

Hannerz M, Aitken SN, King JN, Budge S (1999). Effects of genetic selection for growth on frost hardiness in western hemlock. Can J For Res 29: 509-516.

Harris AS (1978). Distribution, genetics, and silvical characteristics of Sitka spruce. Proceedings of the IUFRO Joint Meeting of Working Parties, British Columbia Ministry of Forestry. Vancouver, Canada.

Hedrick PW (1999). Perspective: highly variable loci and their interpretation in evolution and conservation. Evolution $\mathbf{5 3}$ 313-318.

Hewitt GM (1996). Some genetic consequences of ice ages, and their role in divergence and speciation. Biol J Linn Soc Lond 58: $247-276$.

Hodgetts RB, Aleksiuk MA, Brown A, Clarke C, Macdonald E, Nadeem S et al. (2001). Development of microsatellite markers for white spruce (Picea glauca) and related species. Theor Appl Genet 102: 1252-1258.

Howe GT, Aitken SN, Neale DB, Jermstad KD, Wheelern NC, Chen THH (2003). From genotype to phenotype: unraveling the complexities of cold adaptation in forest trees. Can J Bot 81: $1247-1266$.

Koss JR, Owenby JR, Steurer PM, Ezell DS (1988). Freeze/Frost Data. Climatography of the US No. 20 Supplement No. 1. National Climate Data Center.

Le Corre V, Kremer A (1998). Cumulative effects of founding events during colonisation on genetic diversity and differentiation in an island and stepping-stone model. J Evol Biol 11: $495-512$.
Merilä J, Crnokrak P (2001). Comparison of genetic differentiation at marker loci and quantitative traits. J Evol Biol 14: 892-903.

Mimura M, Aitken SN (in press). Increased selfing and decreased effective pollen donor number in peripheral relative to central populations in Picea sitchensis (Pinaceae). Am J Bot.

Morgenstern EK (1996). Geographic Variation in Forest Trees. UBC Press: Vancouver, $176 \mathrm{p}$.

Perry DJ, Bousquet J (1998a). Sequence-tagged-site (STS) markers of arbitary genes: development, characterization and analysis of linkage in black spruce. Genetics 149: 1089-1098.

Perry DJ, Bousquet J (1998b). Sequence-tagged-site (STS) markers of arbitrary genes: the utility of black spruce-devived STS primers in other conifers. Theor Appl Genet 97: 735-743.

Peterson EB, Peterson NM, Weetman GF, Martin PJ (1997). Ecology and Management of Sitka spruce, Emphasizing its Natural Range in British Columbia. UBC Press: Vancouver.

Peterson MA, Denno RF (1998). The influence of dispersal and diet breadth on patterns of genetic isolation by distance in phytophagous insects. Am Nat 152: 428-446.

Pfeiffer A, Olivieri AM, Morgante M (1997). Identification and characterization of microsatellites in Norway spruce (Picea abies K). Genome 40: 411-419.

Reynolds J, Weir BS, Cockerham CC (1983). Estimation of the coancestry coefficient: basis for a short-term genetic distance. Genetics 105: 767-779.

Redfern DB, Cannell MGR (1982). Needle damage in Sitka spruce caused by early autumn frost. Forestry 55: 39-45.

Rousset F (1997). Genetic differentiation and estimation of gene flow from statistics under isolation by distance. Genetics 145 : 1219-1228.

Rungis D, Berube Y, Zhang J, Ralph S, Ritland CE, Ellis BE et al. (2004). Robust simple sequence repeat markers for spruce (Picea spp.) from expressed sequence tags. Theor Appl Genet 109: 1283-1294.

Sakai A, Larcher W (1987). Frost Survival of Plants. Springer: Heidelberg, Berlin.

SAS Institute Inc. (2000). SAS OnlineDocR, Version 8. Cary, NC.

Schneider S, Roessli D, Excoffier L (2000). Arlequin: a software for population genetics data analysis. User manual ver 2001. Genetics and Biometry Lab, Dept. of Anthropology, University of Geneva.

Scotti I, Magni F, Paglia GP, Morgante M (2002). Trinucleotide microsatellites in Norway spruce (Picea abies): their features and the development of molecular markers. Theor Appl Genet 106: $40-50$.

Sharbel TF, Haibold B, Mitchell-Olds T (2000). Genetic isolation by distance in Arabidopsis thaliana: biogeography and postglacial colonization of Europe. Mol Ecol 9: 2109-2118.

Slatkin M (1993). Isolation by distance in equilibrium and nonequilibrium populations. Evolution 47: 264-279.

Slatkin M (1995). A measure of population subdivision based on microsatellite allele frequencies. Genetics 139: 457-462.

Soltis DE, Gitzendanner MA, Strenge DD, Soltis PS (1997). Chloroplast DNA intraspecific phylogeography of plants from the Pacific Northwest of North America. Plant Syst Evol 206: 353-373.

Spitze K (1993). Population structure in Daphnia obtuse: quantitative genetic and allozymic variation. Genetics 135: 367-374.

Wright S (1943). Isolation by distance. Genetics 28: 114-138.

Wright $S$ (1946). Isolation by distance under diverse systems of mating. Genetics 31: 39-59.

Wright S (1951). The genetic structure of populations. Annu Eugenics 15: 355-420.

Xu P, Ying CC, El-Kassaby YA (2000). Multivariate analyses of causal correlation between growth and climate in Sitka spruce. Silvae Genet 49: 257-263.

Yeh FC, El-Kassaby YA (1980). Enzyme variation in natural populations of Sitka spruce (Picea sitchensis.) 1. Genetic variation patterns among trees from 10 IUFRO provenances. Can J For Res 10: 415-422.

Supplementary Information accompanies the paper on Heredity website (http://www.nature.com/hdy) 